ПЕТУХОВ Роман Владимирович - кандидат юридических наук, магистр социологии (МВШСЭН), старший научный сотрудник Института социологии Федерального научно-исследовательского социологического центра РАН (117218, Россия, г. Москва, ул. Кржижановского, 24/35, корп. 5; petukhovrv@yandex.ru)

\title{
О ПРИЧИНАХ ВОСПРИЯТИЯ МЕСТНЫХ ОРГАНОВ ВЛАСТИ КАК НАИБОЛЕЕ КОРРУМПИРОВАННЫХ ВЛАСТНЫХ И ОБЩЕСТВЕННЫХ ИНСТИТУТОВ СОВРЕМЕННОЙ РОССИИ
}

\begin{abstract}
Аннотация. Особенностью взаимоотношений между простыми людьми и местными властями является возможность их непосредственной и регулярной коммуникации. Многие важные для граждан вопросы могут быть решены только путем обращения в муниципальные органы власти. Однако система публичной власти в современной России организована таким образом, что муниципалитеты не имеют достаточных ресурсов для самостоятельного удовлетворения всех поступающих к ним законных требований граждан. Для многих местных жителей опыт непосредственного взаимодействия с муниципальными властями является крайне негативным, что разрушительно действует на доверие к ним. Одновременно ограниченность ресурсов, которыми могут распоряжаться местные власти, создает условия для коррупционных злоупотреблений со стороны муниципальных чиновников и повышает шансы жителей столкнуться с проявлениями коррупции. Негативное отношение к местным властям усиливает их отчужденность от общества, которая проявляется в попытках отгородиться от граждан бюрократическими процедурами и политикой информационной закрытости.

По мнению автора статьи, даже в условиях сохранения дефицита ресурсов отношение общества к местной власти может быть изменено за счет расширения местной демократии и внедрения принципов открытости.

Ключевые слова: коррупция, доверие, местное самоуправление, местные власти, местная демократия, открытость
\end{abstract}

$\mathrm{B}$ июне 2019 г. Комитет гражданских инициатив представил доклад «Особенности ротации корпуса мэров в современной России», который получил определенный медийный резонанс ${ }^{1}$. Внимание общественности привлекли выводы исследователей, что двумя основными способами завершения карьеры глав российских городов является либо переход на работу в региональные органы власти, либо возбуждение уголовного дела. Согласно докладу, 39 из 263 экс-мэров, включенных в выборку соответствующего исследования, подвергались уголовному преследованию за злоупотребления, связанные с использованием своего должностного положения [Гринева и др. 2019: 31]. Являются ли эти данные действительно новостью для общества? Скорее всего нет, т.к. уверенность в коррумпированности всех уровней власти давно укоренилась в российском общественном мнении. А судя по данным европейских исследований, обеспокоенность коррупцией в органах власти характерна и для жителей многих стран Евросоюза. В частности, согласно данным опроса, проведенного в октябре 2017 г. в рамках проекта Eurobarometer, 2/3 европейцев считают, что коррупция широко распространена в их странах ${ }^{2}$.

Общероссийский опрос общественного мнения, проведенный Федеральным

1 Из мэров в пэры. - Коммерсантб. 27.06.2019. Доступ: https://www.kommersant.ru/ doc/4012955?query=КГИ (проверено 21.10.2019).

2 Corruption. Special Eurobarometer 470. URL: https://ec.europa.eu/commfrontoffice/publicopinion/ index.cfm/ResultDoc/download/DocumentKy/81008 (accessed 30.07.2019). 
научно-исследовательским социологическим центром РАН в октябре 2018 г. в рамках мониторингового исследования «Динамика социальной трансформации современной России в социально-экономическом, политическом, социокультурном и этнорелигиозном контекстах» (далее - Мониторинговое исследование $)^{1}$, позволил выстроить своеобразный рейтинг коррумпированности властных и общественных институтов, 1-е место в котором с большим отрывом заняла власть на местах (см. рис. 1).

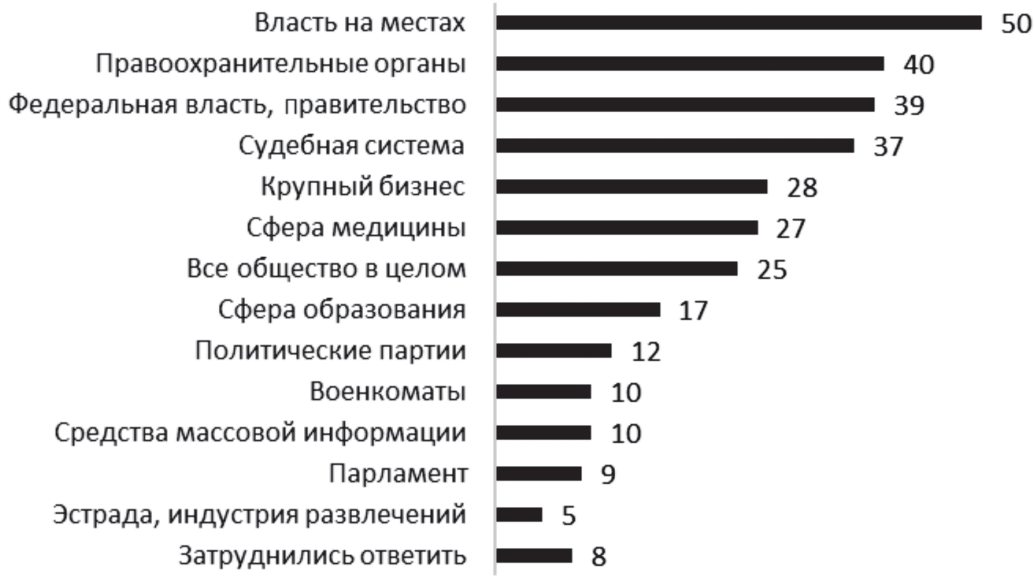

Рисунок 1. Распределение ответов на вопрос, какие институты и сферы жизни современной России, по мнению респондентов, в наибольшей степени поражены коррупцией, \% (октябрь 2018 г.)

Действительно ли муниципальная власть в современной России является наиболее коррумпированной? Это сложный вопрос, для ответа на который, по всей видимости, нужны специальные экономико-статистические исследования, которые в нашей стране пока не ведутся. Данные о числе зарегистрированных преступлений по ст. 290 (получение взятки) и ст. 291 (дача взятки) Уголовного кодекса РФ, доступные на поддерживаемом Генеральной прокуратурой портале правовой статистики ${ }^{2}$, мало что дают для понимания распространенности коррупции в разных органах власти и вреда, который она наносит экономике страны. Тем не менее и без специальных исследований можно утверждать, что коррупция в местных органах власти действительно присутствует. Как справедливо отмечал один из ведущих отечественных специалистов по местному самоуправлению В.И. Васильев, «в условиях системной коррупции местное самоуправление не может быть сферой, свободной от этого зла» [Васильев 2012: 5].

Наиболее распространенным в современной научной литературе является представление о том, что коррупция - это девиация в социально-экономических и отчасти политических отношениях, являющаяся серьезным препятствием для развития любой страны [Shleifer, Vishny 1993; Svensson 2005;

1 В рамках проекта в период с 2014 по 2018 г. каждые 6 месяцев проводились общероссийские опросы, объем выборочной совокупности каждого из которых составлял 4000 респондентов, репрезентируюших взрослое население страны в возрасте 18 лет и старше в разбивке по полу, возрастным когортам, уровню образования и типу поселения.

2 http://crimestat.ru/offenses_map (проверено 21.10.2019). 
Бусыгина, Филиппов 2013]. Некоторые отечественные авторы идут еще дальше и называют коррупцию угрозой национальной безопасности России [Беляков, Чуканова 2014; Латов 2015]. В рамках этого подхода, который некоторые авторы называют структурно-функциональным [Бляхер, Пегин 2012: 90-91], коррупция рассматривается в качестве однозначно противозаконного и негативного явления. Она глобальна и присутствует не только в России, но и в других странах, и даже в международных организациях [Андрианов 2011; Румянцева 2008]. Причем, по мнению ряда ученых, именно в нашей стране коррупция приобрела хронический характер [Левин, Сатаров 2012; Клейнер 2014], а ее уровень сильно превышает соответствующие показатели развитых западных демократий [Бусыгина, Филиппов 2013: 50].

Но есть и другой подход к интерпретации этого явления. Многогранность коррупции позволяет отдельным исследователям не только относить некоторые ее формы к числу относительно приемлемых практик обыденного поведения, но и увидеть в ней не угрозу, а «приводной ремень» экономического развития страны. В этом случае коррупция до некоторой степени перестает быть социальной девиацией (продолжая, однако, оставаться ею в юридическом смысле) и представляется одним из элементов неформальной, или «серой» экономики, обеспечивающей выживание достаточно большой части населения страны. То есть, она понимается как особая система неформальных отношений, позволяющих адаптировать к повседневности формальности бюрократического государства. Такая «коррупция со знаком плюс» была, например, широко распространена в позднем СССР, когда с ее помощью преодолевались препоны административно-распределительной системы [Кордонский 2006]. Позднее, когда страна переживала рыночные реформы, коррупция стала институтом неформального экономического взаимодействия контролеров и контролируемых, имеющим целью снижение транзакционных издержек от следования писанным правилам, установленным властью, или их нарушения [Панеях 2001].

Амбивалентность восприятия коррупции характерна и для российского общества. Это хорошо демонстрируют результаты трех волн общероссийских опросов общественного мнения, проводившихся ФНИСЦ РАН в апреле 2015 г., апреле 2016 г. и октябре 2017 г. в рамках вышеуказанного Мониторингового исследования. В каждой из трех волн респондентам задавался вопрос, какие события, процессы, происходящие в последнее время в жизни страны, вызывают у них тревогу. Как видно из приведенных ниже данных, коррупция неизменно входит в число наиболее беспокоящих россиян проблем. В то же время по результатам каждой из трех волн в «рейтинге тревожности» она ни разу не поднялась выше 5-го места, хотя число респондентов, у которых ее рост вызывает тревогу, к 2017 г. заметно выросло (см. табл. 1).

Такое отношение к коррупции, как представляется, связано прежде всего с тем, что коррупция воспринимается обществом в качестве «привычного зла», с которым чрезвычайно сложно, если вообще возможно, бороться. Особенно если учитывать, что органы власти, призванные бороться с этим явлением, сами ему подвержены.

Если говорить о причинах коррупции как таковой, то, судя по данным названного выше опроса от октября 2018 г., практически половина опрошенных усматривают их в жадности и аморальности российских чиновников (45\%). Почти $1 / 4$ респондентов полагают, что коррупция - это следствие неэффективности государства и несовершенства законов (24\%). В сращивании интересов бюрократии и большого бизнеса усматривают основу для коррупционных практик еще $20 \%$ опрошенных. Наконец, для $11 \%$ она связана с низким уровнем правовой культуры и законопослушания подавляющего числа россиян. Названные 
Таблииа 1

Какие события, процессы, происходящие в жизни страны, вызывают у респондентов наибольшую тревогу*, \%

\begin{tabular}{|l|c|c|c|}
\hline \multicolumn{1}{|c|}{ Варианты ответов } & $\begin{array}{c}\text { Весна } \\
\mathbf{2 0 1 5} \text { г. }\end{array}$ & $\begin{array}{c}\text { Весна } \\
\mathbf{2 0 1 6} \text { г. }\end{array}$ & $\begin{array}{c}\text { Осень } \\
\mathbf{2 0 1 7} \text { г. }\end{array}$ \\
\hline Рост цен на товары и услуги & 72 & 82 & 65 \\
\hline $\begin{array}{l}\text { Кризис системы ЖКХ, рост жилищно- } \\
\text { коммунальных платежей }\end{array}$ & 51 & 58 & 51 \\
\hline $\begin{array}{l}\text { Низкий уровень жизни значительной части } \\
\text { населения }\end{array}$ & 41 & 49 & 43 \\
\hline $\begin{array}{l}\text { Сокращение доступа к бесплатному } \\
\text { образованию, медицинскому обеспечению }\end{array}$ & 36 & 39 & 39 \\
\hline Коррупция, засилье бюрократии & 30 & 26 & 37 \\
\hline
\end{tabular}

* Отобраны 5 вариантов ответов, вызывающих тревогу у наибольшего числа респондентов по результатам опросов, проведенных весной 2015 и 2016 гг., а также осенью 2017 г.

факторы универсальны для всех властных и общественных институтов, но они мало что дают для объяснения причин, по которым именно власть на местах воспринимается в качестве наиболее коррумпированной. Представляется, что искать объяснение этому факту следует в том, как общество в целом относится к этому уровню власти.

Как показывают многочисленные исследования, в современном российском обществе сложилось довольно негативное отношение к местным органам власти, проявляющееся прежде всего в критическом падении доверия к ним. Согласно данным последней волны мониторингового исследования ФНИСЦ РАН, проведенного осенью 2018 г., органам местного самоуправления доверяли лишь 26\% опрошенных, а о своем недоверии к этому уровню власти сообщил каждый второй респондент (51\%). Это связано с целым комплексом причин, среди которых основной, по нашему мнению, является ощущение ее отчужденности от граждан [Петухов 2018: 135-136].

Один из главных специалистов по изучению доверия среди современных социологов Петр Штомпка полагает, что доверие к публичным институтам возникает, прежде всего, из оценки гражданами результатов своего непосредственного взаимодействия с представителями власти и той информации, которую они получают из СМИ [Штомпка 2012: 366-367]. В тех случаях, когда опыт непосредственного взаимодействия с институтом негативен, а опосредованные каналы получения информации о его деятельности недостаточны, недостоверны или критичны, по отношению к нему происходит разрушение доверия. Муниципальные органы являются одним из немногих институтов власти, о которых простые граждане в принципе могут составить представление, не прибегая к опосредованным источникам информации. В любой стране, и Россия в этом случае не является исключением, местные органы власти являются той точкой («интерфейсом» или «приемной»), в которой чаще всего начинается взаимодействие граждан с публичной политической властью при решении ими своих проблем. Более того, для многих людей именно общение с местными чиновниками является основным опытом коммуникации с властью.

Особенностью организации местной власти в современной России является крайняя ограниченность ее ресурсов, что не позволяет ей автономно от 
регионов и федерального центра решать проблемы жителей соответствующих территорий. Между формально закрепленными за муниципалитетами полномочиями, т.е. теми обязанностями, исполнения которых могут требовать граждане, и реально имеющимися в их распоряжении ресурсами имеется существенное несовпадение. Минимальная работоспособность низового уровня публичной власти обеспечивается за счет «ручного» перераспределения ресурсов между муниципальными образованиями и интервенций региональных, а иногда и федеральных властей, направленных на решение вопросов местного значения. Ярким примером такой интервенции является федеральный проект «Формирование комфортной городской среды»1, в рамках которого за счет средств федерального бюджета, распределяемых региональными властями, проводится благоустройство отдельных дворов и парков во многих городах и сельских населенных пунктах страны. Участие местных органов власти в реализации этого проекта минимально и сводится главным образом к определению площадок для благоустройства.

Обращение граждан с теми или иными законными требованиями в органы местной власти и неполучение ими их удовлетворения в силу отсутствия у последних необходимых ресурсов само по себе является негативным опытом и прямо способствует формированию представления об их некомпетентности и несамостоятельности. Однако наиболее сильно на отношение жителей к местным органам власти влияют попытки муниципальных чиновников и депутатов отгородиться от людей и их проблем бюрократическими процедурами и максимально осложнить любые легальные возможности контроля со стороны общества. Насколько эта практика распространена, свидетельствуют данные опроса, проведенного ФНИСЦ РАН осенью 2017 г., показавшие, что 65\% респондентов полагают, что у российских граждан сегодня нет возможности влиять на политику муниципальных (городских) властей; противоположного же мнения придерживаются $35 \%$ опрошенных.

О том, как фактор доступности муниципальных властей влияет на восприятие респондентами степени их коррумпированности, в определенной мере говорят данные от том, жители каких типов поселений чаще других отмечали местные органы власти в качестве наиболее коррумпированных. Исходя из данных последней волны Мониторингового исследования (октябрь 2018 г.), доля критичных ответов в отношении местных властей была наибольшей в административных центрах субъектов РФ (60\% против 50\% в целом по выборке), т.е. в крупных городах, в которых местные органы власти максимально бюрократизированы и закрыты для горожан. И напротив, заметно меньше было тех, кто указал муниципальные власти в качестве в высшей степени коррумпированных, среди опрошенных, проживающих в сельских населенных пунктах и в райцентрах ( $40 \%$ и $47 \%$ соответственно), т.е. именно там, где чаще всего сохраняется физическая и коммуникационная доступность органов местного самоуправления.

Как уже было сказано выше, для многих простых людей обращение в муниципальные органы является преобладающим опытом взаимодействия с властью, соответственно, именно в этих структурах они имеют наибольший шанс столкнуться с коррупцией. Еще больше увеличивает этот шанс ограниченность ресурсов, которыми оперируют местные органы власти. Как отмечает А. Папакостас, «коррупция - это закрытое социальное отношение», которое может быть реализовано только при условии, что кто-то из него будет исклю-

\footnotetext{
1 Федеральный проект «Формирование комфортной городской среды» национального проекта «Жилье и городская среда». - Комфортная городская среда и ЖКХ. Доступ: http://www.gorodsreda.ru/ federal-projects/gorodskaya-sreda/ (проверено 21.10.2019).
} 


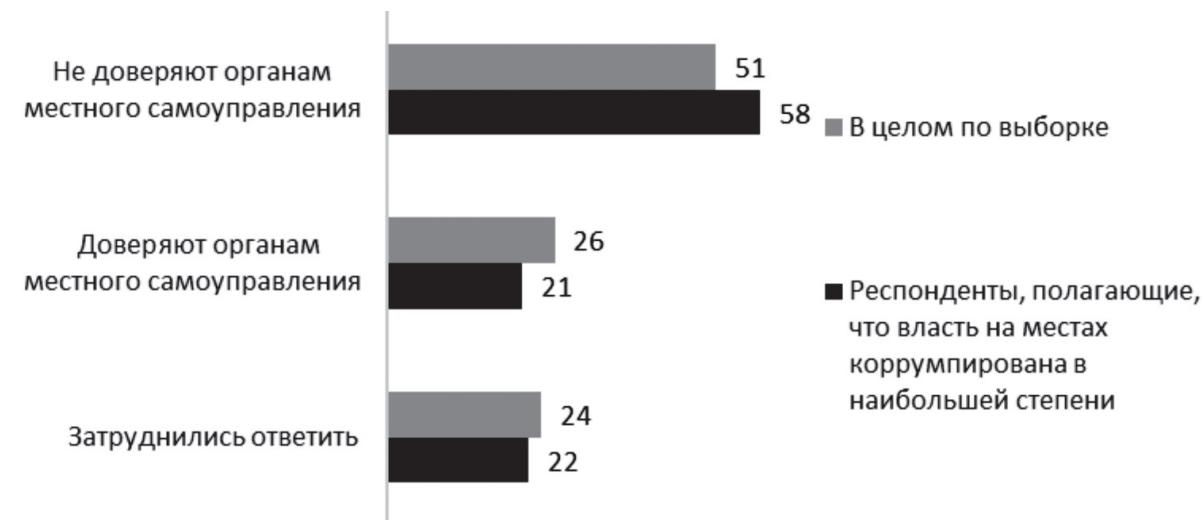

Рисунок 2. Уровень доверия/недоверия к органам местного самоуправления среди респондентов, полагающих, что власть на местах коррумпирована в наибольшей степени, и в целом по выборке, в \% (октябрь 2018 г.)

чен [Папакостас 2016: 137]. Российские муниципалитеты являются как нельзя лучшей средой для формирования такого рода закрытых отношений, т.к. в силу существующей системы распределения полномочий и ресурсов между уровнями публичной власти они изначально не имеют возможности удовлетворять все поступающие к ним требования граждан.

Однако на формирование представления о том, что местные органы власти коррумпированы больше других властных и общественных институтов, влияет не только высокая вероятность непосредственного столкновения граждан с проявлениями коррупции при взаимодействии с ними, но и то, что простые люди плохо представляют, чем в действительности занимаются муниципальные чиновники и депутаты.

Естественно, что представления о коррумпированности муниципальных властей самым непосредственным образом влияют на показатели доверия к ним общества. Как видно из рис. 2, среди респондентов, полагающих, что местные власти в наибольшей степени подвержены коррупции, заметно больше не доверяющих им, чем в целом по выборке (58\% против 51\%), и напротив, меньше доверяющих (21\% против 26\%).

Наиболее существенно на показатели доверия к местным властям влияет опыт участия в отношениях, имеющих коррупционный характер (см. табл. 2). Как и следовало ожидать, минимальный уровень доверия и максимальный уровень недоверия демонстрируют респонденты, неоднократно дававшие взятки представителям местных властей для решения своих проблем. Среди опрошенных, имеющих единичный опыт дачи денег для решения своих проблем, и тех, кто заявил, что никогда не прибегал к подобным методам, заметно больше доверяющих органам местного самоуправления и меньше им не доверяющих. Максимально высокий уровень доверия и минимальный уровень недоверия к местным властям отмечается у той части опрошенных, которые не захотели отвечать на этот вопрос.

Практика показывает, что изменить отношение общества к муниципальным властям даже в условиях сохранения неадекватного распределения ресурсов между уровнями публичной власти можно было за счет внедрения в их деятельность принципов транспарентности и развития местной демократии, предпо- 
Таблица 2

Распределение ответов респондентов на вопрос о доверии/недоверии органам местного самоуправления в зависимости от опыта дачи денег или подарков людям, от которых зависело решение их проблем, \% (октябрь 2008 г.)

\begin{tabular}{|c|c|c|c|c|}
\hline & \multicolumn{4}{|c|}{$\begin{array}{c}\text { Приходилось ли Вам давать деньги, подарки людям, от } \\
\text { которых зависело решение ваших проблем? }\end{array}$} \\
\hline & 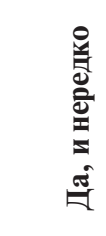 & 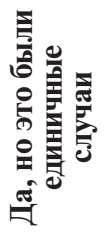 & 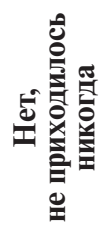 & 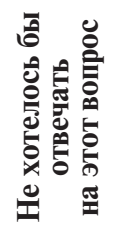 \\
\hline $\begin{array}{l}\text { Доверяю органам местного } \\
\text { самоуправления }\end{array}$ & 19 & 25 & 28 & 29 \\
\hline $\begin{array}{l}\text { Не доверяю органам местного } \\
\text { самоуправления }\end{array}$ & 60 & 51 & 50 & 43 \\
\hline Затруднились ответить & 21 & 24 & 22 & 28 \\
\hline
\end{tabular}

лагающей выборность местных органов власти и их повседневную открытость для взаимодействия с активными гражданами. Показательны в этом отношении также результаты уже указанного общеевропейского опроса, проведенного в рамках проекта «Евробарометр» в $2017 \Gamma^{1}$. Согласно этому исследованию, коррупцию считали широко распространенным явлением более $90 \%$ опрошенных в Греции, Испании, на Кипре, в Венгрии, Литве и Португалии и лишь 21\%, $22 \%$ и $37 \%$ финнов, датчан и шведов соответственно. То есть, минимальные значения восприятия коррупции характерны для граждан стран Северной Европы, занимающей лидирующие позиции в мире по показателям открытости, демократичности их властей. Аналогичным образом распределились ответы и на вопрос, есть ли коррупция в местных и региональных публичных институтах. Если в среднем по Евросоюзу с этим утверждением согласились $72 \%$, а в Греции и Венгрии - 90\% опрошенных, то среди респондентов из Финляндии, Дании и Швеции таких было $36 \%, 40 \%$ и $55 \%$ соответственно.

Очевидно, что выборность и регулярная сменяемость муниципальных руководителей и депутатов, с одной стороны, и активное соучастие местных жителей в управлении муниципальным образованием - с другой, не только способны вернуть доверие, но также являются действенным способом (хотя, конечно, не абсолютным) борьбы с коррупцией. Несмотря на разумность такого подхода к организации местной власти, в России сегодня идут прямо противоположные процессы, следствием которых является все большее отдаление муниципальных властей от жителей. В частности, исходя из данных Министерства юстиции РФ, в нашей стране продолжает сокращаться число глав муниципальных образований, непосредственно избираемых населением на муниципальных выборах (при сравнении данных за 2017 и 2019 гг. - сокращение на 2249 позиций), и существенно увеличивается число глав, назначаемых на свои должности представительным органом из числа кандидатов, отобранных конкурсной

1 Corruption. Special Eurobarometer 470. URL: https://ec.europa.eu/commfrontoffice/publicopinion/ index.cfm/ResultDoc/download/DocumentKy/81008 (accessed 30.07.2019). 
комиссией (при сравнении данных за 2017 и 2019 гг. - увеличение на 2283 позиций) (см. табл. 3). Надо иметь в виду, что последний из этих способов является наименее демократичным, т.к. он не предусматривает ни возможности прямого участия граждан в определении руководителя муниципального образования, в котором они живут, ни каких-либо механизмов предварительного обсуждения с ними кандидатур, выдвигаемых на этот пост.

Таблица 3

Динамика изменения числа глав муниципальных образований всех видов, замещающих свои должности путем выборов и по назначению*

\begin{tabular}{|l|c|c|}
\hline \multicolumn{1}{|c|}{ Число глав муниципальных образований всех видов } & $\begin{array}{c}\text { По состоянию на } \\
\text { 1 марта 2017 г. }\end{array}$ & $\begin{array}{c}\text { По состоянию на } \\
\text { 1 марта 2019 г. }^{2}\end{array}$ \\
\hline Избираемые населением на прямых выборах & 7719 & 5470 \\
\hline Избираемые населением на сходах граждан & 66 & 8763 \\
\hline $\begin{array}{l}\text { Избираемые представительным органом } \\
\text { муниципального образования из своего состава }\end{array}$ & 9647 & 694 \\
\hline $\begin{array}{l}\text { Назначаемые представительным органом из числа } \\
\text { кандидатов, отобранных специальной комиссией по } \\
\text { результатам конкурса }\end{array}$ & 4661 & \\
\hline
\end{tabular}

* По данным Министерства юстиции РФ.

Параллельно с сокращением выборности в органы местного самоуправления идет процесс сокращения числа муниципальных образований и формирования укрупненных муниципальных образований (городских и муниципальных округов), отличающихся большой площадью и числом жителей. Для управления такими большими муниципальными образованиями необходимы полноценные организационно-управленческие структуры (местные администрации) с десятками, а иногда и сотнями штатных профессиональных муниципальных служащих. Вероятность возникновения коррупции в таких бюрократических организациях значительно выше, чем в администрациях городских и сельских поселений, средняя штатная численность которых, согласно указанным выше информационным материалам Минюста России, составляла в начале 2019 г. 8 и 3 чел. соответственно. Как отмечает В.В. Васильев, «коррупция характерна в большей степени для органов местного самоуправления муниципальных районов и городских округов. Чем крупнее муниципалитет и более разветвлен аппарат исполнительно-распорядительных органов, тем чаще в нем гнездится коррупция» [Васильев 2012: 5-6].

Подводя итоги, следует отметить, что муниципальные власти относятся общественным мнением к числу наиболее коррумпированных властных институтов, что в сочетании с их отчужденностью от граждан и сокращением выборности крайне негативно влияет на доверие к ним. Существенную роль в восприятии

1 Информационно-аналитические материалы Министерства юстиции о состоянии и основных направлениях развития местного самоуправления в Российской Федерации (данные за 2016 г. - начало 2017 г.). - Минюст России. Доступ: http://minjust.ru/sites/default/files/monitoring-msu-2017_11283. docx (проверено 21.10.2019).

2 Информационно-аналитические материалы Министерства юстиции о состоянии и основных направлениях развития местного самоуправления в Российской Федерации (данные за 2018 г. начало 2019 г.) - Минюст России. Доступ: https://minjust.ru/sites/default/files/inf_0.docx (проверено 21.10.2019). 
коррупции в органах местного самоуправления играет их закрытость для общества. Исследование показывает, что в коррумпированности муниципальных властей уверены в большей степени жители крупных городов - административных центров субъектов РФ, в то время как жители сельской местности в наименьшей степени склонны разделять эту точку зрения. Представляется, что определенную роль в этом расхождении играет разница в масштабах муниципальных образований, позволяющая городским властям оставаться непроницаемыми для простых граждан и вынуждающая сельских муниципалов к большей открытости. Соответственно, укрупнение муниципальных образований и создание больших по территории и числу жителей муниципальных образований, которое продвигается как способ повышения эффективности муниципального управления, может привести к обратному результату за счет роста коррупции и снижения уровня доверия населения. И напротив, небольшие по территории и числу жителей муниципалитеты, число которых с каждым годом сокращается, могли бы стать зоной, свободной от коррупции. Небольшие по числу чиновников местные администрации сельских и малых городских поселений гораздо легче контролируются со стороны как общества, так и государства.

В то же время нельзя не видеть и то, что коррупция как социальное явление пронизывает не только власть, но и общество, значительная часть которого имеет опыт решения своих проблем за счет подкупа должностных лиц и использования служебных полномочий в своих частных интересах. Исследования показывают, что непосредственное участие граждан в коррупционных отношениях ведет, помимо всего прочего, к снижению их доверия к местным властям. Соответственно, изменить отношение общества к местной власти невозможно лишь изменением масштаба муниципальных образований или какими-либо иными формальными бюрократическими мерами. Справиться с этой задачей можно лишь путем развития местной демократии, делающей местные органы власти открытыми для общества.

\section{Список литературы}

Андрианов В.Д. 2011. Бюрократия, коррупция и эффективность государственного управления: история и современность. М.: Wolters Kluwer Russia. 278 с.

Беляков Б.Л., Чуканова Н.А. 2014. Коррупция как преграда на пути развития предпринимательства и российской государственности. -Инновационные процессы и культура предпринимательства на потребительском рынке товаров и услуг. VI Найденовские чтения: сборник научных статей (под ред. Ю.В. Рагулиной). М.: Московская академия предпринимательства при Правительстве Москвы. C. 198-201.

Бляхер Л.Е., Пегин Н.А. 2012. Коррупция как политическая проблема: кто, как и зачем сражается с коррупцией в России. - Полития. Анализ. Хроника. Прогноз. № 4(67). С. 89-103.

Бусыгина И.М., Филиппов М.Г. 2013. Ограничить коррупцию: найти новых людей или изменить мотивацию? - Полис. Политические исследования. № 1. С. 50-71.

Васильев В.И. 2012. Борьба с коррупцией и местное самоуправление. Журнал российского права. № 4(184). С. 5-17.

Гринева Д.Д., Коротеева П.П., Максимов А.Н., Соснин Д.П., Трудолюбов А.С. 2019. Особенности ротации корпуса мэров в современной России: доклад. М.: Комитет гражданских инициатив. 49 с.

Клейнер В.Г. 2014. Коррупция в России. Россия в коррупции. Есть ли выход? - Вопросы экономики. № 6. С. 81-96. 
Кордонский С.Г. 2006. Рынки власти: Административные рынки СССР и России. 2-е изд. М.: ОГИ. 240 с.

Латов Ю.В. 2015. Коррупция в системе угроз национальной безопасности России. - Актуальные проблемы экономики и права. № 1(33). С. 45-46.

Левин М.И., Сатаров Г.А. 2012. Коррупция в России: классификация и динамика. - Вопросы экономики. № 10. С. 4-29.

Панеях Э.Л. 2001. Формальные правила и неформальные институты их применения в российской экономической практике. - Экономическая социология. T. 2. № 4. С. 56-68.

Папакостас А. 2016. Становление цивилизованной публичной сферы: Недоверие, доверие и коррупция. М.: ВЦИОМ. 224 с.

Петухов Р.В. 2018. К проблеме социального содержания местного самоуправления. - Мониторинг общественного мнения: Экономические и социальные перемены. № 6. С. 131-146.

Румянцева Е.Е. 2008. Коррупция как противоположность демократии. Научный эксперт. № 5. С. 58-64.

Штомпка П. Доверие - основа общества. 2012. М.: Логос. 445 с.

Shleifer A., Vishny R.W. 1993. Corruption. - The Quarterly Journal of Economics. Vol. 108. No. 3. P. 599-617.

Svensson J. 2005. Eight Questions about Corruption. - Journal of Economic Perspectives. Vol. 19. No. 3. P. 19-42.

PETUKHOV Roman Vladimirovich, Cand.Sci. (Legal), Senior Researcher at the Sociological Institute - branch of the Federal Center of Theoretical and Applied Sociology, Russian Academy of Sciences (bld. 5, 24/35 Krzhizhanovskogo St, Moscow, Russia, 117218; petuhovrv@yandex.ru)

\section{ABOUT THE REASONS OF THE PERCEPTION OF LOCAL AUTHORITIES AS THE MOST BRIBABLE POWER AND PUBLIC INSTITUTIONS OF CONTEMPORARY RUSSIA}

\footnotetext{
Abstract. The relationship between ordinary people and local authorities is specific due to ability of their direct and regular communication. Many problems that are important for citizens could only be resolved by contacting the municipal authorities. Nevertheless, the system of public authorities in contemporary Russia does not provide municipalities with enough resources for the implementation of all citizens' legal requirements. Many locals have extremely negative experience of direct interaction with municipal authorities and such negative experience destroys the citizens' trust in authorities. At the same time, the limitation of the local authorities' resources create conditions for municipal officials to make the corruption abuses and increases the chances of citizens to face corruption. The negative attitude towards local authorities reinforces its estrangement from society, which is manifested in the authorities' attempts to isolate themselves from citizens by bureaucratic procedures and by information protection.

The article postulates that even the conditions of a lack of resources, the attitude of society towards local authorities can be changed by expanding local democracy and introducing principles of transparency.

Keywords: corruption, trust, local self-government, local authorities, local democracy, transparency
} 